\title{
Translating Evolving Technology Use into User Stories Technology Life Narratives of Consumer Technology Use
}

Hedman, Jonas; Bødker, Mads; Gimpel, Gregory; Damsgaard, Jan

Document Version

Accepted author manuscript

Published in:

Information Systems Journal

DOI:

10.1111/isj.12232

Publication date:

2019

License

Unspecified

Citation for published version (APA):

Hedman, J., Bødker, M., Gimpel, G., \& Damsgaard, J. (2019). Translating Evolving Technology Use into User Stories: Technology Life Narratives of Consumer Technology Use. Information Systems Journal, 29(6), 11781200. https://doi.org/10.1111/isj.12232

Link to publication in CBS Research Portal

\section{General rights}

Copyright and moral rights for the publications made accessible in the public portal are retained by the authors and/or other copyright owners and it is a condition of accessing publications that users recognise and abide by the legal requirements associated with these rights.

Take down policy

If you believe that this document breaches copyright please contact us (research.lib@cbs.dk) providing details, and we will remove access to the work immediately and investigate your claim. 


\title{
Translating Evolving Technology Use into User Stories: Technology Life Narratives of Consumer Technology Use Jonas Hedman, Mads Bodker, Gregory Gimpel, and Jan Damsgaard
}

\author{
Journal article (Accepted manuscript*)
}

\section{Please cite this article as:}

Hedman, J., Bødker, M., Gimpel, G., \& Damsgaard, J. (2018). Translating Evolving Technology Use into User Stories: Technology Life Narratives of Consumer Technology Use. Information Systems Journal. https://doi.org/10.1111/isj.12232

This is the peer reviewed version of the article, which has been published in final form at DOI: https://doi.org/10.1111/isj.12232

This article may be used for non-commercial purposes in accordance with Wiley Terms and Conditions for Self-Archiving

* This version of the article has been accepted for publication and undergone full peer review but has not been through the copyediting, typesetting, pagination and proofreading process, which may lead to differences between this version and the publisher's final version AKA Version of Record. 


\title{
Translating Evolving Technology Use into User Stories: Technology
}

\section{Life Narratives of Consumer Technology Use}

\author{
Jonas Hedman*, Mads Bødker*, Gregory Gimpel**, and Jan Damsgaard* \\ * Department of Digitalization, Copenhagen Business School, Denmark \\ ** Department of Computer Information Systems, Georgia State University, USA
}

People acquire and buy technology in stores or online in the same way as any other consumer product, so understanding the user as a consumer of technology is essential. In this study, we investigate how the use of ubiquitous consumer technology evolves over time and suggests a theoretical account of how use evolves into different patterns of embodiment. Empirically, we followed 15 consumers of smartphone during a six-month field study and collected data via interviews, survey, and focus groups. Analytically, we view the user as a consumer of technology and develop three technology-life narratives as patterns of embodiment. As a theoretical lens, we draw upon theory of consumption values and approached use as a dynamic consumption process in which different values drive use over time. We found three distinct patterns of embodiment: that of conditionalists, aesthetic socialites, and functional enthusiasts. Conditionalists are pragmatic and use technology only when the device fulfils pre-existing needs and the preferred alternative is unavailable. Aesthetic socialites use the technology as a fashion accessory and to manage their personal relationships. Functional enthusiasts are gadget lovers whose tinkering for the sake of exploration leads them to discover new needs that the technology can fulfil. Besides the three patterns of embodiment, we discovered a type of use that we argue falls outside of the values described in the theory of consumption values. This is the use of technology without any identifiable purpose other than just using the technology, which is driven by expositional value.

Keywords: Embodiment, Technology Use, Consumer technology, Theory of Consumption Values, Technology Life Narratives. 


\section{Introduction}

In this paper, we inquire into the evolving use of technology devices in general and ubiquitous consumer technologies in particular. Many current and near ubiquitous digital consumer technologies are typified by having an ecosystem that includes a large app library, a touch screen, Wi-Fi/cellular data connection, web browser, e-mail, a number of contextual sensors (for e.g. light, tilt, location, proximity), and by being customizable by direct downloads from app libraries (Bødker et al., 2014).

Our interest in such consumer technologies is informed by Weiser's seminal notion of ubiquitous computing (1991). Writing at a time when computers were large, expensive and unwieldy machines, his perspective on the unremarkable nature that computer technologies will have in the future has generated a number of topics and themes in research. One of the key issues of current research is the way in which new computing technologies are embedded into the environments and life worlds of users (Henfridsson \& Lindgren, 2005; Jain, 2003; Mazmanian et al., 2005; Middleton et al., 2014; Prasopoulou, et al., 2006). Furthermore, research based on the phenomenology of the body (e.g. Merlau-Ponty, 2012) has pursued the role of 'embodiment' in human relations to artefacts, e.g. how technologies become unremarkable (Tolmie et al., 2002, Dourish, 2001), and the ways interaction with technologies can take the form of a 'background relation' (Ihde, 1990). The use of ubiquitously digital technology resources and environments designed to become unremarkable or, through use over time, consigned from noticeably 'spectacular' to background relations (Tolmie et al., 2002) is typically not seen as a long term developing practice, but largely as an individual state realized at the point of adoption of a device, see for instance conceptualizations of use building upon expectations (Walsh, et al., 2016) or the IS Success Model (Delone \& McLean, 2003) by Al-Jabri and Sohail (2012). Conceptualizing use as a more static concept assumes that particular approaches to the design of a computer interface facilitates invisibility or transparency of the computer artefacts. This, in turn, is reflected in a number of more or less formalized design approaches and heuristic guidelines (Ishii \& Ullmer, 1997; Norman, 2002; Schmidt, 2000).

There are relatively few empirical studies addressing how the use and experience of such ubiquitous technologies and environments change over time (Stein, et al., 2015; Walsh, 2014). These include Mazmanian, et al.'s (2006; 2013) study of the Blackberry's social implications for work-life balance, Bakardjieva and Smith's (2001) ethnographic account describing the domestication process of the Internet in everyday life, Bødker et al.'s (2014) extended study of use and the transformation of smartphones in everyday life, and Lanette and Mazmanian's (2018) study of addiction measures for smart phone use. To address the gap, Yoo (2010) argues that the IS research community needs to look more systematically at what he calls experiential computing - the ways in which our lives increasingly involve "digitally mediated embodied experiences in mundane activities through everyday artefacts that have embedded computing capabilities" (Yoo, 2010, p. 213). In particular, Yoo emphasizes the need to rethink the notion that computer technologies are tools to transcend time and space, eliminating geographical and temporal barriers. Rather, Yoo argues that computer 
technologies are increasingly entangled in the immediate here-and-now of everyday lives. This entails a process of developing particular actions and value-based dispositions vis-à-vis the technologies one engages with on an everyday basis, a process that can be described as a form of embodiment. Furthermore, Yoo stresses an idea from Lamb and Kling (2003), who argue that researchers should broaden their views on the users to understand them as social actors, embedded in a social context. Baskerville makes a similar argumentation but uses instead the term individual information systems (Baskerville, 2011). Following these ideas of ubiquitous and experiential computing and the user as a consumer, our research addresses is concerned with the following research question:

How do ubiquitous consumer technologies become part of the consumer's life?

To pursue this, we have engaged in a longitudinal field study of 15 users. Following Yoo's (2010) suggestion when investigating experiential computing devices, we view the user as a consumer of technology, drawing upon consumer research and the Theory of Consumption Values (TCV) (Sheth et al. 1991a; b) to collect a rich empirical corpus and to present technology life narratives (TLN) (Sandelowski, 1991). Our study identifies three patterns of how technologies become part of the consumers' life and we propose three user characters: conditionalist, aesthetic socialite, and functional enthusiast, as well as a narrative presentation of the characters' lives, as means of answering the research question. This illustrates how "the art of storytelling" as laid out by Davison (2016) in Information Systems Journal can be used as tool for inquiry by creating compelling narratives as objects for analysis. This paper makes three distinct contributions. First, the paper introduces technology life narratives as a mode of inquiry and as a technique for communicating research insights (Sandelowski, 1991). Second, the resulting stories, with their inherent longitudinal and process perspectives, contribute to the understanding of how the use of ubiquitous consumer technology evolves over time (e.g. Stein et al., 2015). Third, this research contributes to theory of consumption values (Sheth et al. 1991a; b) by identifying a new value, expositional value, which is the use of technology without any identifiable purpose other than just using the technology.

This paper proceeds as follows: The next section reviews literature on post-adoption use. Then we present the theory of consumption values, which is the theoretical lens used to analyse the field study data. We later outline the research approach, and then present and discuss the findings. We follow with a discussion of contribution, limitations, and areas for future research. A conclusion recaps the key points of the paper and brings the paper to a close.

\section{Literature review}


This section provides an overview of research into the use of consumer information technology (IT) and how modern technologies are shaping the ways people experience interactions with others and the world around them. It then introduces the theory of consumption values (Sheth et al., 1991a; b) as a conceptual lens for understanding this technology use.

\section{Use of consumer technologies}

Often new technologies are brought into discourse in a vocabulary of the spectacular and the sublime (Nye, 1996). iPhones (Bødker et al., 2014; Hedman \& Gimpel, 2010), iPads (Skageby, 2011), iPods (Leong et al., 2008; Yang \& Hsu, 2011), smartphones (Alazzawe \& Wijesekera, 2010; Ballagas et al., 2006; Hislop \& Axtell, 2011; Kim, 2010; Pitt et al., 2011; Walsh et al., 2016), and interactive technologies (Kietzmann, 2008) have all been the objects of admiration and awe. The churn of everyday experiential computing devices and their connected ecosystems, however, makes a consistent and ongoing fascination with a technological object difficult. Although smartphones may initially be an object of fascination, over time such new technologies tend to become increasingly unobtrusive, personal, or infrastructural. This in particular goes for devices where screen size, processor capability, interaction regimes, and general portability has enabled them to become what Gellersen, et al. (1999) call "accompanying": unrestrictive with respect to user's mobility or activities and unobtrusive in the user's environment. Mobile phones, PDAs, smart phones, and portable computers are woven into a network of densely available data infrastructures (Bell \& Dourish, 2007; Dourish \& Bell, 2007) and seem to be the realization of Weiser's (1991) vision of ubiquitous computing as an age of unremarkable digital devices and infrastructure (Tolmie et al., 2002). However, while Weiser's proximate future scenarios appealed to fantasies of revolutionary or disruptive technological forces, the current world of everyday ubiquitous computing is arguably messy, uneven, and often less than awe-inspiring in everyday engagement (Dourish \& Bell, 2007).

Research into users' experiences of (and with) digital multi-purpose artefacts such as smartphones is challenging since they are so intricately and invisibly woven into everyday activities and experiences (Jung, et al., 2008). While some scholars have studied the increasing ubiquity of information technology (IT) and the way it permeates everyday life (Castells, 2001; Lamb \& Kling, 2003; Leonardi \& Barley, 2008; Walsh et al., 2016), less attention has been paid to the temporal nature of diminishing representational and aesthetic values that often fall outside the study of work settings and mandatory use situations. Karapanos et al. (2009) provide an exception by exploring user experience as it unfolds over time. They show that while hedonic, beautyrelated qualities of interactive products are seen as important factors in the experience of a product, users readily judge an artefact on pragmatic (i.e., functional and utility related) grounds. While aesthetic and hedonic aspects such as novelty and stimulation play a significant role in early judgments of products, these attributes predictably diminish over time (Karapanos et al., 2009). 
Yoo's (2010) ideas of experiential computing rely heavily on the notion of embodiment; that technology use is always taking place in a physical (embodied) situation where a conscious and corporeal actor has some intentional stance towards the world. Therefore, space is at once the structure of an interaction as well as the product of the interaction with and through a technology towards the world. In other words, the external world of a user can be understood as a world of things and opportunities, mediated through and given meaning by the available technologies. Similarly, time is an emergent property of the intentional stance towards the world. Yoo uses this phenomenological outset to see experiential computing as unremarkable computing (Tolmie et al., 2002) in the sense proposed as a design direction by Weiser (1991). Yoo goes on to state that with computing capacity migrating en masse into everyday artefacts "[h]umans will no longer experience computing as something that is out there, but rather they will live in it" (Yoo, 2010, p. 220). However, this does not explain the actual process of evolving into a state where technology becomes, in this way, unremarkable, ubiquitous, and mundane. In this paper, we use the term 'patterns of embodiment' to describe different ways in which a technology becomes part of the users dispositional qualities of engagement with her or himself as well as the value-laden social world around them. This includes practices, as well as corporeal dispositions, feelings and cognition. Importantly, a pattern of embodiment is an emergent process. It entails a continuous becoming a user, subject to a wide variety of changing life circumstances as well as changes in the technological and infrastructural landscapes of IT.

\section{Theory of Consumption Values}

As Yoo (2010) points out, a key role that people have in everyday life is that of consumer - one who consumes the goods and services produced. The role as a consumer of technology diverges from the more established conceptualizations - the one role a user of technology often in a work context. Much of the information systems theorizing takes its outset in a work context and thereby overlooks the role as a consumer. Recently, however, with the consumerization of IT and the bring-your-own-device movement, focus has shifted to consumer IT (Bødker et al., 2009; Venkatesh et al., 2012). Our search for a complementary view of the user leads us to consumer research, which focuses on humans in their role as consumers. The theory of consumption values (Sheth et al., 1991a; b) is one of the more comprehensive synthesis of consumer research is and has been extensively used to understand different consumer decisions, including choice of green products (Lin \& Huang, 2012), use of peer grading (Pope, 2001), and value of purchasable game items (Park \& Lee, 2011). Although TCV was established within the consumer research domain several years ago, the TCV has appeared only recently within information systems research. The TCV offers a tool for researching people's choice of using or not using a technology (Hedman \& Gimpel, 2010) and ubiquitous computing devices (Bødker, et al., 2009). It includes many of the concepts that underlie the disparate perspectives currently employed within adoption and use of technology research, such as the theory of reasoned action (Fishbein \& Ajzen, 1975) and the diffusion of innovations (Rogers, 1995). As such, the TCV incorporates the foundational concepts of key 
adoption and use research while at the same time broadening the perspective with which to approach technology use. It also explicitly incorporates the work of Hirschman and Holbrook (1982) that inspired scholars to call for the consideration of hedonic motivations (Van der Heijden, 2004; Venkatesh et al., 2012), and for social and emotional constructs (Bagozzi, 2007; Turel et al., 2010). The TCV has been applied in technology studies, such as researching the decline in software value over time (Alpert, 1994), internet banking (Ho \& Ko, 2008), smart phones (Jung, 2014), ringtones as hedonic IT artifacts (Turel et al., 2010), and hyped technology (Hedman \& Gimpel, 2010). In addition, there are calls for extending TCV in longitudinal studies to understand changes in consumer values (Pousa \& Nuñez, 2014).

The theory assumes that decisions, such as to use or not to use, are based on values (Sheth et al., 1991a; b). Consumption values address extrinsic and intrinsic reasons and motives that drive decisions. It includes five different types of values that underlie consumption decisions. According to the TCV, a particular choice may be determined by one value or influenced by several values. The values are as follows.

Functional value stems from an alternative's perceived utility for accomplishing a specified task or achieving a practical goal. It follows economic utility theory, assumes economic rationalism, and relates to attributes such as performance, price, and reliability. Consumer decisions to buy or use a product or service are based on the attributes of the focal object and how well they fulfil the consumers' utilitarian needs (Sheth et al., 1991a; b). For example, someone may use the Uber app on their smartphone to get from one location to another. In this instance, the goal is to reach a destination and the phone's app is the means by which the consumer achieves that end.

Social value involves highly visible products, services, and/or objects to be shared with others (such as gifts). According to the TCV, such an item may be chosen more for its perceived social image than for its functional performance. Essentially, social value is derived from the symbolic importance of an artefact (Sheth et al., 1991a; b). Consider someone who waits in line all night to be the first to get an Apple Watch so that his friends will hold him in high regard as a tech-savvy trendsetter.

Epistemic value applies when consuming or experiencing new products or services, such as buying a new computer or mobile phone. Epistemic value stems from novelty, the ability to arouse curiosity, a desire to learn, or the urge to experiment with something new (Sheth et al., 1991a; b). One instance would be beta testers of new applications and services that want to experience something novel.

Emotional value influences decisions because of a product's potential to arouse emotions that are believed to accompany the use of a product. Aesthetics, such the beauty and artistry of a well designed or smart looking device, can add emotional value to a product (Sheth et al., 1991a; b). A traveling businessperson may derive emotional value from a mobile device that enables her to experience the joy of reading bedtime stories to her children when she is away.

Conditional value applies to products or services for which the value is strongly tied to use in a specific context. A temporary functional or social value arises when the circumstances create a need (Sheth et al., 
1991a; b). For example, a Verizon network phone provides value in the United States, but may offer no value Europe where the mobile service providers use different technology.

\section{Research Approach: Technology Life Narratives}

Technology life narratives (TLNs) is an approach to present a rich empirical corpus in order to contribute to the understanding of evolving use of ubiquitous consumer technology. TNLs follows calls by for instance Clausen (1994) who argued that technologists need to understand IT users in ways that acknowledges that they are both "human beings" and "living people." Clausen argues that narrative forms are effective for going beyond the communication facts to formulate and express conceptualizations about complex situations. It follows, Bruner's cognitive/functional theory of narration (1990), that assumes all human experience and sense making can be viewed as a process of narration. The narrative form is part of an attempt to contextualize and order the multi-layered reality of people's experiences. Sandelowski (1991) explains that "the goal of narrative explanation is to provide an intelligible, comprehensive, and very similar narrative rendering of why something happened" and that narratives must be "well-grounded and constitute [a] supportable emplotment of events (actions and intentions) (p.164, emphasis added). Similarly, Czarniawska-Joerges (2004) asserts that both individuals and organizations are best understood as storied: produced, reproduced, and understood as narratives with distinct temporal and dynamic properties (Hoefnagel et al., 2014; Lawler, 2002).

Our approach assumes that this multi-layered experiential reality of people's lives can be meaningfully engaged with by giving it a coherent narrative form (Polkingthorne, 2007). It does not claim that the narratives we have created are the only ways of inquiring into and relating experience. Certainly, other stories might have been told from the data gathered. For our research, we did not explicitly solicit narratives or retellings from our participants during interviews. Rather than being biographical retellings of experiences by the participants (Holway \& Jefferson, 2000), the narratives emerged through the researchers' iterations between collecting data, analysing the data, and reporting the findings within a theoretical structure. From this interplay, the narratives were developed as plausible plots of events and later, combined with the theoretical frame of TCV, as the constituents of our findings.

TLNs are somewhat similar to work carried out by anthropologists who, by way of detailed observation, create rich ethnographic accounts of cultural practices, occasions or phenomena. These are conveyed in the form of believable as well as suggestive narratives of people's actions, experiences, belief systems and so on. TLN focuses on distinguishing different behavioral patterns rather than give a full account the voluminous details collected as part of a longitudinal field study. We suggest that the approach of writing up observational data is also a means of inquiry (Richardson \& St. Pierre, 2005). The meaning making as well as the more formal analytical movements in a research process are not necessarily external to the crafting of technology life narratives, but part and parcel of the method of telling plausible stories based on empirical 
work. When arguing for rigor in IS research, Lee and Hubona (2009) evoke Sanday's (1983) argument that research should convey human behavior in ways such that a layperson stranger would be able to understand the behavior. Lee and Hubona also draw upon Schutz's (1962) argument that research should provide interpretations of everyday life as it is practiced and understood through the immediate, inter-subjective, "common sense" perspective of actors. Accounts of everyday life with technology should strive to enter into a broader public discourse by remaining accessible and meaningful to non-academic as well as people outside of particular academic disciplines.

In this sense, TLNs use narratives as a means of ordering and creating a cohesive structure on the texts created in our data collection. The narrative form requires a beginning, middle, and end; therefore, a particular temporal perspective is integral to any narrative approach. Creating narratives provides an increased sensibility for understanding dynamic aspects of use over time.

\section{Creating Technology Life Narratives}

Writing TLNs is an iterative process. To some extent, it resembles the approach to personas advocated by Cooper et al. (2007), who encourage the condensation of findings about specific technology users in 'fictional' characters that are nevertheless backed by data. Presenting data in this way allows for the presentation of the rich descriptions that come from anecdotes. It is through this type of data that we are able to explain the relationships among participant data. The process of creating a TLN involves three main phases: data collection, the writing of individual narratives (including feedback on the narratives by participants), and the creation of TLNs as objects for a theoretically informed analysis using the frame of consumption values.

\section{Phase one-data collection}

Our study commenced in August 2008, coinciding with the release of the Apple iPhone 3G. Sixteen participants received the iPhone and a basic service plan (voice, SMS, data) for 6 months (August 2008 to March 2009). They were selected from a graduate-level e-business program. The mixed gender group ranged in age from 22 to 51 and worked full- or part-time. One participant's hardware failed during the first week and consequently the participant was dropped from the study.

To ensure data triangulation and to follow the evolution of usage behaviour, we collected data through multiple data sources, including three surveys (beginning, middle, and end of study), three focus groups, media diaries, traffic data from the mobile operator, and 60 interviews (see Table 1 for a summary). The surveys allow us to compare data over time using consistent measures. The focus groups "bring out individual "participant's views, experiences, and beliefs because individuals are often unaware of their own implicit perspectives until they interact with others on a topic" (Morgan, 1997, p. 46). Media diaries, a variation on diary methods in qualitative inquiry, primarily focusing on the practices with- and perceptions of media (Couldry et al., 2010), were used to capture the general media technology usage through self-reporting (Berg \& Düvel, 2012). Our media diaries allowed for, but did not mandate, more open personal reflections 
(Vandewater \& Lee, 2009). The tracking of mobile traffic data reduces limitations caused by overreliance on self-reported usage, which can reduce data validity in IS research (Burton-Jones \& Straub, 2004; Straub et al., 1995). The interviews allow pursuing clarification from participants and to make sure that all participants provide the necessary data points about their experiences.

Table 1. Data collection

\begin{tabular}{|c|c|c|c|c|c|}
\hline Data collection & Participants & Time & Interviewers & Duration & Focal point \\
\hline Pre survey & 16 & Aug 2008 & N/A & N/A & Self-reported usage \\
\hline Traffic data & 15 & $\begin{array}{l}\text { Aug 2008- } \\
\text { March } 2009\end{array}$ & $\begin{array}{l}\text { Provided by } \\
\text { the operator }\end{array}$ & $\mathrm{y} N / A$ & $\begin{array}{l}\text { Actual use of phone, } \\
\text { SMS, and amount of } \\
\text { data traffic }\end{array}$ \\
\hline Focus groups 1-3 & $5+4+5$ & Oct 2008 & One + one & $2: 00 * 3$ & Adoption and use \\
\hline Interview A & 15 & Nov 2008 & One & $0: 30$ & $\begin{array}{l}\text { Exploration of usage } \\
\text { behaviour }\end{array}$ \\
\hline Media diary & 15 & Oct 2008 & Self-reported & & Technology use \\
\hline Interview B & 15 & November 2008 & Two & $0: 30$ & $\begin{array}{l}\text { Probing of the } \\
\text { device's usefulness }\end{array}$ \\
\hline Mid Survey & 15 & Dec 2008 & N/A & N/A & Self-reported usage \\
\hline Interview C & 15 & March 2009 & One (Skype) & $1: 00$ & $\begin{array}{l}\text { Changes in adoption } \\
\text { and usage behaviour }\end{array}$ \\
\hline Interview D & 15 & March 2009 & Two & $1: 00$ & $\begin{array}{l}\text { Usage in relation to } \\
\text { other technologies }\end{array}$ \\
\hline End Survey & 15 & March 2009 & $\mathrm{~N} / \mathrm{A}$ & N/A & Self-reported usage \\
\hline $\begin{array}{l}\text { E-mail } \\
\text { of } \quad \text { verification } \\
\text { narratives }\end{array}$ & 12 & December 2011 & $\mathrm{~N} / \mathrm{A}$ & & $\begin{array}{l}\text { Comments on } \\
\text { individual narratives }\end{array}$ \\
\hline
\end{tabular}

\section{Phase two - individual technology-life narratives}

In the second phase, we wrote time sensitive, individual narratives for each of the 15 participants. We treated each participant as an individual case and structured all empirical data accordingly, including survey materials, interviews, media diaries, focus groups, and traffic data. The first step was to code the data according to the five consumption values and how use progressed over time. Secondly, for each participant, we wrote a narrative of approximately 1000 words which we later condensed to approximately 350 words. The storyline in the narratives focused on how participant use evolved from the beginning to the end of the study and how each user's consumption values changed over time. We construct individual narratives as the first step to creating higher-order TLNs, which helps us capture the essential elements within our large data set (Remenyi \& Williams, 1996). The individual narratives follow Eisenhardt's (1989) recommendation to write-up each case as a way to become intimately familiar individual experiences. This allows the analysis of patterns with each case before performing a cross-case analysis to be able to generalize patterns across cases. In table 2, we show the TLN and the coding of participant no 2. 
Table 2. Coding and Technology Life Narrative of participant no 2

\begin{tabular}{|c|c|c|}
\hline Time period & TLN & Coding \\
\hline Beginning & $\begin{array}{l}\text { She particularly remembers a situation where she got some positive } \\
\text { interest in her new phone by some strangers on the metro. She feels } \\
\text { somehow proud to have that nice piece of hardware. On the other hand, } \\
\text { she feels a bit guilty about flashing it too much, as she is very much a } \\
\text { student with limited funds - how could she afford this iPhone is a } \\
\text { question she'd rather not get. So she pre-emptively often tells people } \\
\text { that she is participating in a study and got the phone from there. She } \\
\text { doesn't use email on the phone, but likes some of the more kooky apps } \\
\text { available - for example, the "lighter" app. The iPhone can be fun and } \\
\text { entertaining, but she uses a regular phone most of the time. She } \\
\text { wouldn't spend a lot of money on this sort of thing, and prefers not to } \\
\text { pay a lot for flat rate data. She is not inclined to experiment a lot with } \\
\text { getting the phone to substitute for already existing technologies she has, } \\
\text { but she finds the phone entertaining and nice. }\end{array}$ & $\begin{array}{l}\text { Social } \\
\text { Emotional } \\
\text { Epistemic }\end{array}$ \\
\hline Middle & $\begin{array}{l}\text { Curiously, at some point she found (and used) an app that helps her } \\
\text { count the knots when she is knitting. She thinks it is neat, but also a bit } \\
\text { comical, using your phone when knitting. Otherwise, the phone is still } \\
\text { basically a phone, not something for browsing or mailing, for which she } \\
\text { would much rather use her laptop. }\end{array}$ & Conditional \\
\hline End & $\begin{array}{l}\text { She is now applying for a job and has begun using the email on the } \\
\text { iPhone - she relates much of this usage to curiosity over whether or not } \\
\text { she got the job. She has also begun using "social" apps such as } \\
\text { Facebook, mostly because she is curious about her friends - is } \\
\text { something interesting happening right here, right now? She also reads } \\
\text { books on the phone when in "idle" situations, such as waiting for the } \\
\text { bus. She is not completely convinced that the iPhone is her phone of } \\
\text { choice - she still considers other phones - but she has found the iPhone } \\
\text { fun. At least, it is good to have if you are out of range of your laptop or } \\
\text { other technologies that you use on a regular basis. }\end{array}$ & Conditional \\
\hline
\end{tabular}

Because individual TLNs are abstractions that summarize a lengthy process of a real person's experience, we present the individual TLNs to the respective participant for verification. Each written narrative was sent to the relevant individual participant through e-mail for their feedback. Of the 15 participants, 12 
commented on their individual narratives; most participants gave brief comments and suggestions, while some gave substantial feedback and additional interpretations of their use of the iPhone. This verification by participants helps correct any errors before they are built into the study findings, helping to ensure the rigor of the study (Morse et al., 2002). Additionally, this reflexive step in our analysis helps us make sure that our narratives are truly reflective of the people represented in this study (Kincheloe \& McLaren, 2002). Once the individual TLNs were verified, they were used as input for the development of more abstract TLNs that can provide a broader understanding of more general patterns of technology embodiment.

\section{Phase three-technology-life narratives}

In the abductive process of analyzing the individual narratives with the TCV theoretical lens, we began to notice patterns in the consumption values that seemed to explain evolving technology use. We analysed each TLN so that we could compare across the different cases and could corroborate experiences. This allows us to identify patterns while eliminating chance associations that are not part of a generalizable explanation. This enables us to generalize patterns across the experiences of the participants (Eisenhardt, 1991). As a result, we can present more parsimonious understanding of evolving technology use (Remenyi \& Williams, 1996). In table 3, we show the relationship between the fifteen individual narratives and the three TLNs. The categorization of the individual narratives relates the end phase of the use period. The first pattern is the conditionalists, which is formed around the iPhone as a context-based substitute for other technologies (i.e. conditional value). The second pattern is the aesthetic socialites, which draws upon aesthetic appreciation and symbolic (emotional and social values) use of the technology as a fashion accessory. The third pattern is the functional enthusiasts, which is related to tinkering and exploration of the device's capabilities (epistemic and functional values).

Table 3. From individual narrative to patterns of embodiment

\section{Patterns of embodiment}

\begin{tabular}{cllll} 
Participant & \multicolumn{1}{c}{$\begin{array}{c}\text { Early } \\
\text { consumption } \\
\text { values }\end{array}$} & consumption values & $\begin{array}{c}\text { End } \\
\text { consumption values }\end{array}$ & $\begin{array}{c}\text { Technology Life } \\
\text { Narratives }\end{array}$ \\
\hline & $\begin{array}{l}\text { Functional } \\
\text { Social } \\
\text { Emotional } \\
\text { Epistemic }\end{array}$ & $\begin{array}{l}\text { Functional } \\
\text { Epistemic }\end{array}$ & Functional & Functional Enthusiasts \\
Social & Conditional & Conditional & Conditionalists \\
Emotional & $\begin{array}{l}\text { Epistemic } \\
\text { Social } \\
\text { Epistemic } \\
\text { Emotional } \\
\text { Conditional }\end{array}$ & Epistemic & Emotional & Aesthetic socialites \\
Emotional & Emotional & & \\
4 & Social & Functional & Functional Enthusiasts
\end{tabular}




\begin{tabular}{|c|c|c|c|c|}
\hline 5 & $\begin{array}{l}\text { Conditional } \\
\text { Emotional }\end{array}$ & Conditional & Conditional & Conditionalists \\
\hline 6 & $\begin{array}{l}\text { Epistemic } \\
\text { Functional } \\
\text { Social } \\
\text { Emotional } \\
\text { Epistemic }\end{array}$ & $\begin{array}{l}\text { Functional } \\
\text { Epistemic }\end{array}$ & Functional & Functional Enthusiasts \\
\hline 7 & $\begin{array}{l}\text { Conditional } \\
\text { Emotional } \\
\text { Epistemic }\end{array}$ & $\begin{array}{l}\text { Epistemic } \\
\text { Conditional }\end{array}$ & Conditional & Conditionalists \\
\hline 8 & $\begin{array}{l}\text { Conditional } \\
\text { Social } \\
\text { Epistemic } \\
\text { Emotional }\end{array}$ & $\begin{array}{l}\text { Conditional } \\
\text { Social }\end{array}$ & $\begin{array}{l}\text { Social } \\
\text { Conditional } \\
\text { Emotional }\end{array}$ & Aesthetic socialites \\
\hline 9 & $\begin{array}{l}\text { Conditional } \\
\text { Social } \\
\text { Epistemic } \\
\text { Emotional }\end{array}$ & $\begin{array}{l}\text { Conditional } \\
\text { Social }\end{array}$ & $\begin{array}{l}\text { Social } \\
\text { Emotional }\end{array}$ & Aesthetic socialites \\
\hline 10 & $\begin{array}{l}\text { Social } \\
\text { Epistemic } \\
\text { Emotional }\end{array}$ & $\begin{array}{l}\text { Epistemic } \\
\text { Conditional } \\
\text { Social }\end{array}$ & Social & Aesthetic socialites \\
\hline 11 & $\begin{array}{l}\text { Functional } \\
\text { Epistemic }\end{array}$ & $\begin{array}{l}\text { Functional } \\
\text { Epistemic }\end{array}$ & Functional & Functional Enthusiasts \\
\hline 12 & $\begin{array}{l}\text { Emotional } \\
\text { Epistemic }\end{array}$ & $\begin{array}{l}\text { Functional } \\
\text { Conditional }\end{array}$ & Conditional & Conditionalists \\
\hline 13 & $\begin{array}{l}\text { Functional } \\
\text { Epistemic }\end{array}$ & Functional & Functional & Functional Enthusiasts \\
\hline 14 & $\begin{array}{l}\text { Social } \\
\text { Epistemic }\end{array}$ & $\begin{array}{l}\text { Emotional } \\
\text { Conditional }\end{array}$ & Conditional & Conditionalists \\
\hline 15 & $\begin{array}{l}\text { Emotional } \\
\text { Epistemic }\end{array}$ & $\begin{array}{l}\text { Functional } \\
\text { Conditional }\end{array}$ & Conditional & Conditionalists \\
\hline
\end{tabular}

\section{Findings: Technology-life narratives}

In the following section, we present the three TLNs. The conditionalists are pragmatic and use technology only when the device fulfils pre-existing needs. The aesthetic socialites use the technology as a fashion accessory. The functional enthusiasts are gadget lovers whose tinkering for the sake of exploration leads them to discover new needs that the technology can fulfil. To tell the TLNs, we use allusive names, which reflect the use patterns, not specific individual participants.

\section{The Conditionalist}

Condielisa is quite curious to see and hold her new iPhone. Is it really as nice as they say? She unwraps it and begins setting it up. As she retrieves it from the packaging, she finds it curious that hardly any instructions are provided. Compelled by curiosity to see the phone in action, she charges it and figures out how to start up the phone using iTunes. It is a little bit of a hassle and she misses not having the instructions. Oh, now it works. She turns on the phone and makes a test call to a friend and puts it in her bag. It works. Great! It's a part of the 
kit now. Going on-line via her Wi-Fi at home? Sure. It works. Now, a bit of television and then off to bed. Some days later, Condielisa is in class and a group of them discuss what they feel is so great about the iPhone. Condielisa has a hard time coming up with stuff she feels is truly different or ground breaking. Of course, the phone looks quite different; you can go on the web and so on, but really not that different from her laptop. It's just there when you need it.

A few weeks later Condielisa is using her laptop for e-mail, Facebook, and such things. She is also using her laptop for things like writing and searching for information. Occasionally, if she is away from her laptop, she checks her mail and Facebook on the iPhone. She has not changed the home screen on her phone, keeping it as it was when it came out of the box. She has not bothered to download anything from the app store. Oh, well, there was that little free "lighter" app that could be fun to use at a concert, but that is about it. She tried to make her calendar sync with the one she uses on her laptop on a daily basis because she heard it could be really useful, but it proved to be something of a hassle. So, she decided that she didn't really need it and stopped trying to make it work. It's been five months since she got the iPhone. Sure, it's nice and she does still occasionally check her mail on it, mostly to keep up with what's coming her way, since she applied for a new job. For Condielisa, the main use is still calling and texting, coordinating with other people when out and about, and for occasional entertainment, there is always YouTube (for the nephew and niece when they come for a visit) or as something to kill time on the train back from university.

\section{The Aesthetic Socialite}

Esther likes beautiful things. She had heard a lot of the iPhone hype and saw an ad for it online. It looked very cool, and definitely exciting. Now, sitting at home and unboxing the device, she absolutely is not disappointed. She admires the weight of the iPhone, the rounded corners, the clarity of the screen, and touching and swiping the phone. The next day on the street, she gets a kick out of taking out her phone, checking for news or taking a picture, almost (but just barely) feeling a pang of embarrassment in flashing the device. In the metro on her way to university, she meets someone she knows peripherally. He raises an eyebrow as she takes out her brandnew iPhone. "Wow, what's that?" As she steps out of the metro, she feels her day is a tad brighter because he asked.

After having it for a few weeks, it has the odd scratch here and there, but is still feels like something of a trophy. She always has it and she has begun playing around with it a bit, installing this and that, but she is particularly fond of the way in which it supports her social life. A few days ago, she had the experience of being with a group of people, discussing the name of the author of The Wizard of Oz. "L. Frank Baum...18561919," she states, smiling. The iPhone is increasingly empowering. It makes life feel light, things are accessible, close, easy to manage. It's a coveted object that, apart from being nice to look at, holds her whole life inside it, including all the pictures she took while in Rome during the fall and snapshots of her friends and 
family. She is concerned that the phone might break or that she might lose it, but she hasn't gotten around to actually syncing the phone with whatever program on her laptop would store the images.

After a while she still uses her laptop for most things. However, keeping in touch with people is increasingly done on the iPhone using Facebook, and she also uses it to call people and write text messages. It's with her everywhere now. Even if the iPhone is increasingly common now, she still enjoys it and finds fun things to do with the phone. If she is away from the phone, she not only misses its functions, but feels as if a part of her is missing. That little thing does so much! On a vacation without the phone, she was almost desperate for it, feeling naked or lost somehow. As the end of the study draws closer, knowing she'll have to hand the phone in to the researchers, she still feels that the iPhone is a coveted piece of hardware, a little jewel that will be very hard indeed to relinquish.

\section{The Functional Enthusiast}

The reaction of Technology Ted, as he likes to be called, to getting an iPhone is initially one of enthusiasm. He has been reading blogs on his MacBook, and this phone is a sure game-changer. Of course he's curious. Is it as good as they say? Does it really live up to the hype? He's heard all the reviews and hearsay about the iPhone, but he has a feeling that it could be too toy-like for his taste. Ted has some experience with "clever" phones, and has good knowledge of what the iPhone could potentially do for him - particularly in terms of providing him with work related stuff such as calendars, e-mail and access to important news. He has never been one to talk much on the phone, though, and he keeps texting to a minimum.

As the weeks pass, Ted sets up e-mail on his phone and becomes one of the go-to guys in class when others have questions about their phones. Although most things are great with the phone, he is constantly finding things that he wishes were different. There's the annoying auto-spell correct thing and that keyboard that he cannot really get used to. And there are some things that make him want to actually "jailbreak" the phone to release its full potential. Clearly, he realizes that the device is quite powerful, it can do things for him for sure. If only he could get under the hood and tweak it a bit, it would definitely enhance his productivity at work and university and make him more efficient.

He tries a range of apps - some for leisure and some for work - and plays around with them. Games can be addictive for a while, and they are obviously great when you have time to kill. Most apps, however, tend to disappear after a little while. After a few months he's found a balance between what's useful and what's not, and while he still buys apps and tries out a few new things, Ted becomes just about satisfied with the device. His initial qualms about the phone being too toy-like have all but gone. Even if he tends to go for "practical" rather fun or fancy, he has come to really appreciate the phone and what it does for him. It's still not the design of the hardware or the clever interface that attracts him to it (the device seems nice but maybe a little too fragile, a brittle thing to hold); it's that it allows him to stay up-to-date on events, to get important 
e-mails during the day, and how well it integrates with his calendar and e-mail systems at work. In short, it helps him go about his day and get things done.

\section{Discussion}

In order to understand how ubiquitous technologies, become part of the consumer's life, this paper identifies three patterns of embodiment, conditionalist, aesthetic socialites, and functional enthusiasts, that demonstrate how technology use evolves over time. The TLNs as well as our analytical stance draw on a vocabulary from consumer research aimed at an understanding of users as consumers of technology (Sheth et al., 1991a; b). We began analysing our research participant's consumption of technology before extending the analysis to suggest patterns of embodiment. In suggesting that the narratives are patterns of embodiment, we emphasize the ways in which the smartphone integrated into our participants everyday life and embodied, here-and-now activities (i.e. how it wove itself in and out of the users concerns with relative value, aesthetic attributes, or functional characteristics, oscillating between being at the centre of attention to become an unobtrusive background resource).

In this section, we first discuss the similarities and differences between the three patterns. Thereafter, we discuss factors that potentially shape the evolving values of the people comprising each pattern. This section also discusses the expositional value experienced by users that is not captured by the TCV.

\section{Patterns of Embodiment}

Use in the narratives followed three distinct patterns and they share one important commonality. First, the interest in the consumer technology among all participants was initially driven primarily by social, emotional, and/or epistemic consumption values. Several participants had an unclear idea of what the iPhone could do. Those with specific expectations about the capabilities of the phone focused more on the drawbacks than on the perceived benefits. For example, participants expected poor web browsing experiences because they knew high speed cellular coverage was not available in many parts of the city. They also knew that this early generation iPhone could not shoot video and had below average camera resolution. Therefore, while functional value played a part in generating interest in the iPhone, its role was immaterial compared to other consumption values. The iPhone represented something new and novel, conveying strong epistemic value. It was an expensive, cutting-edge status symbol, generating social value. The participants - and much of the public at large - had developed an emotional affinity for the device, even before they had owned or even held one. The TLNs arose from the way in which the consumption values that drove device usage changed over time, and from how the shift in the five consumption values changed the users' relationship with the technology. 


\section{Embodiment as conditionalists}

After their first exposure to the phone, conditionalists experienced a marked decline in the consumption values that drove their initial desire to adopt the phone. Any social value they derived from the phone was fleeting and felt passions that spurred pre-adoption interest waned immediately because they experienced no emotional release and no discernible feelings toward the phone. The phone did not seem to change their lives - they only used it for the same utilitarian functions for which they had used their previous phone or other IT device. They only used basic functions, and only used non-phone features when another alternative was not available. Much of the iPhone's value was conditional depending upon the availability of a laptop computer with an internet connection. Generally, when a computer was near and connected to the internet, the computer was the preferred device. When time was limited, a computer's longer boot up time added conditional value to the iPhone, which was ready for use. When a Wi-Fi or landline internet connection was unavailable, the conditional value of the smart phone rose dramatically because it was the only choice.

Conditionalists have integrated computing into daily life and do "not necessary see computing as an activity that is separate from their everyday activities" (Yoo, 2010, p. 220). In fact, surfing the web and email communication are as integrated as reading a newspaper or carrying on a conversation. At the same time, the iPhone as an artefact remains partially distinct from daily practice. The unavailability of other life-integrated artefacts raises conditional value, but it also draws focus on the artefact. While the everyday activities are still mediated by computers, the artefact choice can change the way the user experiences the activity.

\section{Embodiment as Aesthetic socialites}

Almost immediately after getting their iPhones, the aesthetic socialites formed an emotional bond with it almost like love at first sight - much of which was based on the elegant design of the device, at least at the beginning. They seemed motivated by the response they received from those around them. They described it as being a fashion accessory that projected a positive image of the users and they relished the attention they received for being one of the first to have such a coveted device. In the early stage of use, they were driven by epistemic values to explore how the different phone features could help elevate their social status or bond with other people. At this stage, they used their new technology to connect with other iPhone users, forming new social identities based around the aesthetics of the device. They also placed a heavy emphasis on the iPhone's ability to keep them connected via phone, SMS, Facebook, and other app enabled communication. By the midpoint of the study, the aesthetic socialites' curiosity with the device had dropped, and epistemic value ceased to be an important motivator for use. This type of user, however, continued to enjoy flashing the device in public and, even though more people had it, they still felt the iPhone elevated their social status. They were driven by emotional attachments to their connected lives and described their constant checking of Facebook and other activities as habitual, perhaps a bit compulsive. By the end of the study, the aesthetic socialites had come to define part of their social presence through their ubiquitous personal technologies - both because they 
were in the "club" of owners and because so much of their emotional connection to others was now mediated through their iPhone.

The iPhone mediates a significant amount of the aesthetic socialites' social experiences and reflections upon their self-identity. Their connections with other people are increasingly mediated through technology be it the online interactions with their social networks or interfacing with the emotional expressive media that recalls social memories. It also changes the nature by which the actor interacts with others, even when the interaction is direct. For example, many person-to-person conversations involved the iPhone as a source of conversational currency. So even when not used as a medium through which one experiences everyday life, the artefact itself becomes part of everyday activities and identities.

\section{Embodiment as functional enthusiasts}

The functional enthusiasts are self-proclaimed gadget lovers, who immediately after getting the phone experienced a high from increased social value as their friends lauded them for being the first to get an iPhone. But such social values vanished quickly, as others in their peer group got their own iPhones or similar device from other manufacturers. Their curiosity, however, drove them to continue to explore the phone. At first, epistemic value motivated them to experience the cutting-edge interface, to try all the basic features of the phone, and to experiment with various apps. By the middle of the study, much of the novelty of the device was gone, but the functional enthusiasts still found themselves driven by epistemic value to learn about the more sophisticated nuances of the device, such as the ability to jailbreak it and install unauthorized programs. During the study, as the functional enthusiasts explored the different technological features, the functional value of the phone rose. Unlike the conditionalists whose need for embedded features remained constant from before the adoption process, the evolving use and constant experimentation changed the functional enthusiasts' definition of the technology. They found new functions and new uses that became necessities for them. By the end of the study, they had exhausted most of the novelty and satisfied their curiosity, wiping out much of the epistemic value that drove their early use. Instead, they had gone on to discover important uses of the phone and found their use to be driven by functional value.

The artefact directly shapes the lived experiences of functional enthusiasts. The functional enthusiast initially experiences a time of anticipation - wondering what new experiences the iPhone could make possible. The artefact becomes a social actor, invoking a felt need to interact with or optimise the device. In the beginning, the device was a thing to be discovered, understood or optimise, where it later became a partner for everyday activities. Functional enthusiast assimilated the iPhone most completely into their activities, so that once the epistemic value waned, the computing device was an integrated part of their everyday activities.

\section{Summary of pattern of embodiment}

While the three narratives show common consumption values in the early adoption stage, the drivers changed for each group during the course of the study. Shortly after the adoption, the conditionalists fell into a motivational pattern that stayed steady for the remainder of the study. The functional enthusiasts, on the other 
hand, experienced drops in the adoption drivers that occurred were replaced by functional value. Only the aesthetic socialites were still driven by the same values that motivated them in the adoption stage, albeit only 2 of the 3 original drivers still played a material role in their usage. Table 4 summarizes the values that drove the usage for the participants in each TLN, followed by a more detailed analysis.

Table 4. Summary of Consumption Values over time

\begin{tabular}{|l|l|l|l|l|}
\hline & \multicolumn{5}{|c|}{ Changes over time } \\
\hline TLN & Adoption & Early & Mid & End \\
\hline Conditionalists & Social & Social & Conditional & Conditional \\
& $\begin{array}{l}\text { Emotional } \\
\text { Epistemic }\end{array}$ & Epistemic & & \\
\hline Aesthetic socialites & Social & Social & Social & Social \\
& Emotional & Epistemic & Emotional & Emotional \\
& Epistemic & Emotional & & \\
\hline Functional enthusiasts & Social & Epistemic & Epistemic & Functional \\
& Emotional & Social & Functional & \\
& Epistemic & & & \\
\hline
\end{tabular}

\section{Evolving Consumption Values}

The previous section discussed how the different TLNs evolved. This section provides insight into why they evolved the way they did. The three TLNs in this study are unique, so are the motives for the changes into the consumers' use of technology.

\section{Conditionalists' Evolving Values}

The social value that drove conditionalists' initial interest in the phone quickly waned because the exclusivity vanished as the devices diffused through the community. Participant 7 explains: "...people are less curious and less interested in talking about it," a sentiment elaborated upon by Participant 15: "All my colleagues have one, so it's not interesting to them." As with many innovations, novelty decreases as it becomes more pervasive and curiosity declines as one's familiarity with it increases. While they experimented with their iPhones early in the study, by the middle of the study their experimentation had more or less stopped.

Once conditionalists settled into particular usage patterns, emotional value disappeared. They became accustomed to the aesthetics, and they realized that the connectivity offered by the iPhone merely duplicated the connections afforded by their other devices. Participant 15 summarizes this emotional evolution: "It's like a girlfriend. In the beginning, it's fun and sexy, but after half a year, the excitement is gone."

Conditionalists ultimately found only conditional value in the iPhone because they base their use of new technology on previously established norms and routines. Participant 4 explains how the omnipresent connectivity of the iPhone has not changed her perception of where and when to use technology. She explains that she has no interest in bringing computing activities to new contexts. She explains: "I don't sit at home and say 'I want to sit on a [park] bench and surf." Participant 5 elaborates: "The perception of it - you'd have to 
change your whole perception about the situation in which you use the internet. You're locked into using it the old-fashioned way. It's difficult to get people to move out of their comfort zone."

\section{Aesthetic Socialites Evolving Values}

Aesthetic socialites find little functional or conditional value because they continue to use many of their other devices. Novelty (i.e. epistemic value) dissipates as they quickly become accustomed to the device. Participant 8 summarizes the experience: "New stuff is satisfying, of course. How could it not be?" She continues: "After a while, it's like: 'OK, it does it. It is normal."'

Whereas other users initially enjoyed the social value of an expensive object of conspicuous consumption, these users want others to view them as tech-savvy, expert users. Participant 10 explains: "It must be high tech, cutting edge and fashionably designed. This is important because it tells my surroundings about me, my interests, and my preferences." Participant 8 describes it as a personal branding statement, but also explains how this statement creates social value: "It brings people together and creates and inner circle."

While all three user types initially are driven by emotion, aesthetic socialites' emotional connection with the iPhone stands the test of time. Unlike the others whose emotional connection with the device is limited to storing photographs and accessing social media, the aesthetic socialites both view their devices as toys and they actively engage in finding ways the technology can enhance their emotional state. Participant 10, an amateur musician, uses his iPhone to inspire him, both through music and apps. He declares: "It can awaken creativity. I'm a musician as well. I can come up with new ideas. Music puts me in a different mindset thinking in a different way when you work." Participant 8 downloaded relaxation apps. She also explains the playful relationship with the iPhone shared by the aesthetic socialites: "It is quite fun to have these small applications. It is like small toys... I love it. You can download a lot of things. Just to know that is quite fun.” For aesthetic socialites, this fun play begins with an a priori attachment that Participant 9 describes as "...like being in love. You have to touch it all the time." It later becomes as ubiquitous as the device itself, leading Participant 3 to confess "My girlfriend calls it my mistress."

\section{Functional Enthusiasts' Evolving Values}

The functional enthusiasts are technology power users. Unlike the aesthetic socialites, who found sustained social value through the iPhone, functional enthusiasts never derived much social value from the iPhone as a signal of their technological savvy. Like the conditionalists, they initially derived social value from the iPhone's high price. Participant 11 describes the initial perception of the device as being "like gold chains or expensive cars. It's a fashion icon. 'Look, I can afford this iPhone. I have money.” As more people adopted the iPhone, it no longer afforded its cachet as a rare, expensive object to envy. Functional enthusiasts also experienced a decline in social value because as more expert users in their social circles gained fist-hand experience with the device, many noticed its shortcomings. This lowered the social value of the iPhone. Participant 11 explains that the declining image of the iPhone among IT power users began to create negative social value - iPhone users were criticized for spending too much money for the limited functionality it 
afforded. By the middle of the study, functional enthusiasts found themselves in the position of defending their decision to purchase an iPhone.

As technologists, functional enthusiasts were curious about what the iPhone could do. This stimulated emotional excitement and curiosity (i.e. both emotional and epistemic value). They explored development tools and fed their intellectual curiosity by reading about new ways to use the iPhone. They viewed it as a toy to play with. But as they exhausted their experiments, the excitement dissipated as well. At the end of the study, Participant 6 declared "I'm really bored with the iPhone." Participant 11 elaborates: "At first it was a toy; now it's a regular thing."

As skilled users who experimented with all the phone's capabilities, functional enthusiasts found lasting utility in their devices. They all define their smartphones as computers and they use it to perform the same types of functions they would on a desktop or laptop. Because they always have it with them, they make extensive use of these computing functions everywhere and all the time.

\section{Expositional Value}

In the process of writing the individual narratives and the TLNs, we discovered use that could not be explained by functional, social, emotional, epistemic, or conditional value. It was a type of unexplainable use that we label expositional value - use as an end by itself. In coining the term expositional value, we draw upon Jensen's (1995) use of the concept of time-in/time out consumption of media as either inside of everyday practical consciousness (time-in) or outside, in a separate social sphere that suspends everyday activities. Jensen suggests a difference between time-in media use as a practical resource and time-out media use as having the character of a circumscribed 'exposition' or as an end-in-itself. Bødker et al.'s (2014) concept of time-in/timeout concept of smartphone use, utilize the conceptual pair to distinguish between use as a reflected or habitual end by itself ("time-out") or use to achieve a practical goal ("time-in"). Expositional value is "time-out", in the sense that it suggests consumption as a time out of the "practical consciousness" described in Giddens (1984), rather than as a practice-oriented resource. Expositional value applies primarily to aesthetic socialites and functional enthusiasts. For example, while waiting for a bus or riding a train, an aesthetic socialite checks Facebook or flips through photos stored on the phone. These actions are not so much to satisfy an emotional need to perform a particular role as a social actor on Facebook, but rather as a way to "kill time" or to stave off boredom. Similarly, a functional enthusiast may check work email or open a productivity app to fill otherwise idle time. While there may be benefits to performing these actions, they no longer relate to technology, but have become habitual, mundane or backgrounded activities.

This type of expositional value changes the perception of time. Time moves more quickly when people are distracted from time cues, which is why reading a book on a train can make the journey seem faster than looking out the window at passing train stations (Eastwood et al. 2012). Consumer technologies expositional value can focus people's attention away from practical concerns or a well-known, habituated and mundane 
everyday life, possibly reducing boredom caused by the occasional inability to engage one's attention (Eastwood et al., 2012). This experiential need to keep consciousness focused drives a significant amount of consumer behaviour (Csikszenthmihalyi, 2000). While "time killing" may not be a strong driver of the adoption of ubiquitous consumer technologies, it may play a significant role in the ways a technology is accepted by a user and how it is appropriated as a stand-by resource that may unnoticeably modulate embodied dispositions and behavioural patterns. This could be the suggested difference between "lean back" and "lean forward" technology use (Katz, 2010) that indicate types of behaviour as well as embodied stances or schemas.

\section{Contributions and Limitations}

The conditionalists, aesthetic socialites, and functional enthusiasts show patterns of embodiment and provide an easy-to-grasp typology of technology users that offers a different perspective from, for instance, the adopter categories defined by Rogers (1995). Whereas Rogers provides insight into who will adopt at which stage in the technology lifecycle, the TLNs developed in this paper provide insights into how the technology is used and how use will evolve over time. As such, our user classification complements existing research by adding a consideration of the ways in which a person wants to use a technology to the well-established user categories that are based on a person's innovativeness. In more detail, this paper makes three distinct contributions to research that we will elaborate upon in the following sections.

\section{Technology Life Narratives}

The use of TLN as a mode of knowledge production, as a method for inquiry (Richardson \& St. Pierre, 2005) and as a technique for communication of research insights (Czarniawska-Joerges, 2004) is directly linked to the call for paper on "Storytelling and Information Systems" and complements existing research patterns laid out by e.g. Stein, et al., 2015; Walsh, 2014; Mazmanian et al. 2006; 2013; Bakardjieva \& Smith, 2001; Lanette \& Mazmanian, 2018; Bødker et al., 2014. It builds on the principle that narratives can help make sense of how people respond and react to a phenomenon (Czarniawska-Joerges, 2004) and that the iterative writing process is a means of inquiring into behavioural patterns, arrangements and configurations of technology in everyday life. By exploiting data points, the resulting narratives further become a novel presentation of findings based on conventional data collection methods, such as interviews, focus groups, and media diaries. Furthermore, it provides a structure so that abstract data, such as changing nature of technology use can be communicated. This satisfies the Schutz's (1962) criteria of providing an interpretation of everyday life that can be understood through common sense perspectives and is able to convey behaviour in a way that a layperson stranger could understand it, as per Sanday (1983).

As a form of narrative research, TLNs configure "characters, themes and events into a sequence that leads up to the phenomenon to be explained, or understood, and aims to render this phenomenon intelligible 
within the context presented in the narrative" (Llewellyn, 1999, p. 7). Technology life narratives are not universally generalizable. Instead, the patterns presented in TLNs focus on how technology use can evolve, rather than trying to predict the specific way it will evolve, enhancing the ability of researchers to grasp everyday life with digital technologies and infrastructures. This is very much similar with Walsham's argument that research can make meaningful generalizations through the "discussion of generalizations as tendencies rather than predictions" (Walsham, 1995, p. 80). Thus, TLNs can serve as vehicles for assessing and refining theoretical assumptions.

\section{Evolving Technology Use}

This study contributes to the understanding of evolving technology use, by developing theoretical insights in forms of narratives into the evolving of use of consumer technology (Sandelowski, 1991) and its pattersn of embodiment - conditionalists, aesthetic socialites, and functional enthusiasts. Patterns of embodiment describes the way in which the technology and the user 'merge' in particular ways and with particular social, practical, and aesthetic/emotional disposition as the result. The users in this study consume (i.e. use) the hardware, software, and services bundled in the technology without regard for traditional boundaries such as work vs. home or hardware vs. software. The consumption and embodiment patterns vary based on individual needs and preferences. The type of activity that once defined business or personal use have merged, as people use e-mail, mobile services, internet, etc. for both business and personal reasons. The study was designed with the acknowledgement that such traditional distinctions are becoming irrelevant, and that people who use IT are first and foremost consumers of technology (Yoo, 2010). This study marks an important contribution by adding to the lexicon of research acknowledging these vanishing boundaries and in recognizing the consumerization of ubiquitous computing.

\section{Consuming Technology}

By drawing on TVC, we follow Yoo's (2010) call to understand technology users as consumers, which opens a new perspective to technology use (Elie-Dit-Cosaque \& Straub, 2011). For instance, the aesthetic socialites in this study demonstrate how the broad-based TCV can capture motivation that may be missed. Similarly, the novelty value that drove the functional enthusiasts to tinker with their devices is not a common IS construct, and therefore would not be captured by the information systems continuance paradigm, cf. Bhattacherjee and Lin (2015).

The TCV not only captures motivation that other theories would overlook, but our research has also shown its suitability to study continued - and changing - use of technology. As demonstrated in this paper, the TCV can follow shifting usage drivers and it acknowledges that different motivations can push initial behaviour versus subsequent usage. The TCV does not posit that people's motivation is static, an assumption 
that may be appropriate for business environments, but may be problematic in studying consumer situations and the here-and-now sense of what a technology does for and to you. This is an essential contribution to the study of technology use. Only one of the three TLNs that emerged in this study - the aesthetic socialites seemed driven by the same motivations throughout the study. Additionally, the conditionalists continued to use their technology, despite low satisfaction and a lack of confirmation of their a priori expectations. While lower usage rate may correspond with lower satisfaction, the TCV reveals that the use is driven by a completely different factor: the availability or absence of preferred devices. This challenges the assumption that dissatisfaction is the principal factor for the discontinuance of a technology. This study shows that other factors can override or otherwise mitigate dissatisfaction. As such, this study reinforces the arguments that expectation-confirmation and satisfaction, while appropriate in some circumstances, may not provide a comprehensive explanation for continued technology use (Ortez de Guinea \& Markus, 2009).

Although one could argue that demonstrating the theoretical usefulness of TCV would be a meaningful theoretical contribution, this paper's contribution to theory is the further development of TCV as an information systems research tool. While the TCV contains five values that determine consumption decisions, increasingly the use of technology has become a motivation and an end in itself. Drawing upon study data and the resulting TLNs, as well as the theoretical work by Jensen (1995), Steeg-Larsen (1998), and Bødker et al. (2014), we enhance the TCV by adding exposition value as a sixth consumption value. Exposition value reflects users' desire to keep consciousness focused and reduce boredom. By expanding the TCV, we update the theory to remain suitable for the age of anywhere, anytime, any-purpose technology. Expositional value can be used to investigate topics such as "snacking" as well as technology addiction, which is becoming an increasingly prevalent problem among consumers using IT (Bødker et al., 2014; Turel et al., 2011).

\section{Practical implications}

The approach and the findings presented in the paper have implications for practitioners and in particular for designers of everyday digital technologies. In particular, any approach that rests on an assumption that technology becomes invisible in use over time or indeed might be 'unobtrusive by design' (Tolmie et al., 2002), needs to understand and provide for way of integrating rich insights about the emergence of (digital) practices in everyday life. TLNs attempt to address the challenge of diverging patterns of technology consumption. Similar to using design scenarios to provide detailed narratives of use-cases (Carroll, 2000; Cooper et al. 2007), both the writing and presentation of TLN's can be used to analyse and elicit future experiences and use patterns, enabling designers and developers to see various distinct styles of appropriation of technology. However, where the focus in scenarios are predominantly on describing key events of practice, TLN's add a viewpoint of value-based behaviours, feelings, and issues of identity. Rather than depicting a circumscribed task, a particular set of consumption values determines the starting point and dominates the viewpoint of a TLN. Using the TLN, designers can begin to structure and present a dynamic consumption 
processes, thereby addressing long term patterns of experience with technologies. The consumption values framework provides a theoretical scaffold for reasoning about how users may appropriate new technologies, and it provides a frame for narrating dynamic patterns of user experience as it unfolds over time.

\section{Limitations and future research}

This study of how consumer technology use evolves faces some limitations. The choice of a sensationalized technology may create stronger expectations among the participants than other technologies. Although the participants included a wide range of tech savviness and technical experience, the participants may have a greater affinity toward technology than the population at large. The data were collected during the introduction of the iPhone 3G. As such, the experiences presented in the technology life narratives may seem dated, given that smartphone technology and the supporting digital ecosystems have matured since data were collected. However, ubiquitous digital consumer technologies, such as smartphones, are still typified with the same functionality and features. While this is a limitation, the period of time studied represents the most recent paradigm shift of information technology. The iPhone created an inflection point in which computing shifted from primarily an enterprise-based activity to one in which consumers became the largest user base. As such, it provides an opportunity to study how the drivers of adoption, early use, and subsequent continued use of new consumer technology change over time. Aside from the choice artifact, another limitation is that while we have identified some reasons why consumption values change for different user types, the TLNs focus on how consumption values change, but not on why they change.

Future research can expand the investigation into ubiquitous technologies and similar "always-withyou" artefacts. These devices are redefining the nature of IT and it is important that researchers as well as practitioners are prepared for the 'post-stationary' world of computing. Future research should also consider the differing roles users play, rather than viewing them as simply users or consumers of technology. This will require that we not only theorize the artefact, but also the artificial system, which includes the artefact and the user as an ecosystem. Furthermore, we believe that, in order to conceptualize the users, we need new adoption and user typologies beyond Rogers' well-established diffusion of innovations model. New research can build on the three TLNs presented in this paper, as well as develop other narratives. As we have seen, the narrative approach using stories as analytical objects, provides us with a rich source from which to view peoples experience and explore emergent value judgments. Future studies might be concerned with the development of measurements for classifying user typologies, but could also include working further on developing user stereotypes into more rich characterizations to better relate the complexity of user experience in a world of ubiquitous and pervasive IT. In this way, the narrative approach taken in the TLNs could be taken up in designoriented information systems research to extend well established design approaches such as personas and scenarios (Cooper et al., 2007). 


\section{Conclusion}

This paper contributes to the understanding of consumer technology use as a dynamic embodiment process that is motivated by values that may change over time. The blurring of work-home and utilitarian-hedonic technology distinctions motivates the ontological position that technology users are first and foremost consumers of technology, providing an alternative to the employee-centric theories that have historically advanced our understanding of technology. Accordingly, we apply the TCV (Sheth et al., 1991a; b), which includes a robust range of both intrinsic and extrinsic motives that allow us to trace how the values that drive technology consumption evolve over time. Rich data from multiple sources, including interviews, focus groups, surveys, operator data, and media diaries leads to grouping user experiences into three TLNs (Sandelowski, 1991): that of conditionalists, aesthetic socialites, and functional enthusiasts. The data also entailed use that could not be explained by theory of consumption values, leading us to propose expositional value.

\section{Acknowledgements}

This work was carried out with the support by the DREAMS project via a grant from the Danish Agency of Science and Technology (grant number 2106-04-0007) and by the Department of Digitalization at Copenhagen Business School. We also thank the reviewers and the editors for their constructive comments and feedback.

\section{References}

Al-Jabri, I. M., \& Sohail, M. S. (2012) Mobile banking adoption: Application of diffusion of innovation theory. Journal of Electronic Commerce Research, 13(4), 379-391.

Alazzawe, A., \& Wijesekera, D. (2010) A testbed for large mobile social computing experiments. International Journal of Sensor Networks, 8(2), 89-97.

Alpert, F. (1994) Innovator buying behavior over time. Journal of Product \& Brand Management, 3(2), 5062.

Bagozzi, R. P. (2007) The Legacy of the Technology Acceptance Model and a Proposal for a Paradigm Shift. Journal of the Association for Information Systems, 8(4), 244-254.

Bakardjieva, M. \& Smith, R. (2001) The Internet in Everyday Life: Computer Networking from the Standpoint of the Domestic User. New Media Society 2001; 3(1),; 67-83

Ballagas, R., Borchers, J., Rohs, M., \& Sheridan, J. G. (2006) The smart phone: A ubiquitous input device. Pervasive Computing, 5(1), 70-77.

Baskerville, R. (2011) Individual information systems as a research arena. European Journal of Information Systems, 20(3), 251-254.

Bell, G., \& Dourish, P. (2007) Yesterdayís tomorrows: notes on ubiquitous computing'sís dominant vision. Personal and Ubiquitous Computing, 11(2), 133-143.

Berg, M., \& Düvel, C. (2012): Qualitative media diaries: An instrument for doing research from a mobile media ethnographic perspective. Interactions: Studies in Communication \& Culture 3(1), 71-89 
Bhattacherjee, A. (2001) Understanding information systems continuance: An expectation-confirmation model. MIS Quarterly, 25(3), 351-370.

Bhattacherjee, A. \& C.-P. Lin (2015) A unified model of IT continuance: three complementary perspectives and crossover effects. European Journal of Information Systems 24(4), 364-373.

Blechar, J., Constantiou, I. D., \& Damsgaard, J. (2006) Exploring the influence of reference situations and reference pricing on mobile service user behaviour. European Journal of Information Systems, 15(3), 285-291.

Bødker, M., Gimpel, G., \& Hedman, J. (2009) The user experience of smart phones: a consumption values approach. 8th Global Mobility Roundtable, GMR.

Bødker, M., Gimpel, G., \& Hedman, J. (2014) Time-out/time-in: the dynamics of everyday experiential computing devices. Information Systems Journal, 24(2), 143-166.

Bruner, J. (1990) Acts of Meaning. Cambridge, MA: Harvard University Press.

Burton-Jones, A., \& Straub, D. W. (2004) Minimizing method variance in measures of system usage. In the proceedings of the Southern Association for Information Systems (SAIS), 336-342.

Carugati, A., W. Fernández, L. Mola and C. Rossignoli (2018) My choice, your problem? Mandating IT use in large organisational networks. Information Systems Journal, 28(1), 6-47.

Castells, M. (2001) The Internet galaxy: Reflections on the Internet, business, and society. Oxford: Oxford University Press.

Clausen, H. (1994). Designing computer systems from a human perspective: the use of narratives. Scandinavian Journal of Information Systems, 6(2), 1.

Cooper, A., Reiman, R., \& Cronin, D. (2007) About Face 3: The Essentials of Interaction Design. Indianapolis: Wiley Publishing, Inc.

Couldry, N., Livingstone, S., \& Markham, T. (2010) Media consumption and public engagement. Beyond the presumption of attention. New York: Palgrave MacMillan.

Csikszentmihalyi, M. (2000) The costs and benefits of consuming. Journal of Consumer Research, 27(2), 267-272.

Czarniawska-Joerges, B. (2004) Narratives in Ssocial Sscience Rresearch: Sage.

Davison, R. M. (2016) The art of storytelling. Information Systems Journal, 3(26), 191-194.

Delone, W. H., \& McLean, E. R. (2003) The DeLone and McLean model of information systems success: a ten-year update. Journal of Mmanagement Iinformation Ssystems, 19(4), 9-30.

Deng, L. Q., Turner, D. E., Gehling, R., \& Prince, B. (2010) User experience, satisfaction, and continual usage intention of IT. European Journal of Information Systems, 19(1), 60-75.

Dourish, P. (2001) Where the Action is. The Foundations of Embodied Interaction. Cambridge, MA. MIT Press.

Dourish, P., \& Bell, G. (2007) The infrastructure of experience and the experience of infrastructure: meaning and structure in everyday encounters with space. Environment and Planning B: Planning and Design, 34(3), 414-430.

Eastwood, J. D., Frischen, A., Fenske, M. J., \& Smilek, D. (2012) The unengaged mind: Defining boredom in terms of attention. Perspectives on Psychological Science, 7(5), 482-495.

Eisenhardt, K. M. (1989) Building theories from case study research. Academy of Management Review, $14(4), 532-550$.

Eisenhardt, K. M. (1991) Better Stories and Better Constructs: The case for rigor and comparative logic. Academy of Management Review, 16(3), 620-627.

Elie-Dit-Cosaque, C. M. and D. W. Straub (2011) Opening the black box of system usage: user adaptation to disruptive IT. European Journal of Information Systems, 20(5), 589-607.

Fishbein, M., \& Ajzen, I. (1975) Belief, Intention, and Behavior: An introduction to theory and research.: Addison-Welsey, Readings, Mass.

Gellersen, H., Schmidt, A., \& Beigl, M. (1999) Ambient media for peripheral information display. Personal and Ubiquitous Computing, 3(4), 199-208.

Giddens, Anthony (1984) The Constitution of Society. Cornwall: Polity Press.

Hedman, J., \& Gimpel, G. (2010) The adoption of hyped technologies: a qualitative study. Information Technology and Management, 11(4), 161-175. 
Henfridsson, O., \& Lindgren, R. (2005) Multi-contextuality in ubiquitous computing: Investigating the car case through action research. Information \& Organization, 15(2), 95-124.

Hirschman, E. C., \& Holbrook, M. B. (1982) Hedonic Consumption: Emerging Concepts, Methods and Propositions. Journal of Marketing, 46(3), 92-101.

Hislop, D., \& Axtell, C. (2011) Mobile phones during work and non-work time: A case study of mobile, non-managerial workers. Information and Organization, 21(1), 41-56.

Ho, S. H., \& Ko, Y. Y. (2008) Effects of self-service technology on customer value and customer readiness The case of Internet banking. Internet Research, 18(4), 427-446.

Hoefnagel, R., Oerlemans, L., \& Goedee, J. (2014) How anchoring and adjusting influence citizens' acceptance of video-mediated crime reporting: A narrative approach. The Journal of Strategic Information Systems, 23(4), 305-322.

Hollway, W., \& Jefferson, T. (2000) Doing Qualitative Research Differently: Free Association, Narrative and the Interview Method, Sage Publications.

Ihde, D. (1990) Technology and the Lifeworld. From Garden to Earth. Bloomington and Indianapolis. Indiana University Press.

Ishii, H., \& Ullmer, B. (1997) Tangible bits: towards seamless interfaces between people, bits and atoms. In the Proceedings of CHI '97, March 22-27, 1997.

Jain, R. (2003) Experiential computing. Communications of the ACM, 46(7), 48-55.

Jensen, K.B. (1995). The Social Semiotics of Mass Communication. London: Sage Publications

Jung, H., Stolterman, E., Ryan, W., Thompson, T., \& Siegel, M. (2008) Toward a framework for ecologies of artifacts: how are digital artifacts interconnected within a personal life? Proceedings of the 5th Nordic conference on Human-computer interaction: building bridges. October 2008, Lund, Sweden, $18-22$

Jung, Y. (2014) What a smartphone is to me: understanding user values in using smartphones. Information Systems Journal, 24(4), 299-321.

Karapanos, E., Zimmerman, J., Forlizzi, J., \& Martens, J. (2009) User experience over time: an initial framework. Proceedings of the SIGCHI Conference on Human Factors in Computing Systems. April 7th, 2009, Boston, MA, USA.

Katz, H. (2010). The Media Handbook: A Complete Guide to Advertising Media Selection, Planning, Research, and Buying, $4^{\text {th }}$ edition. Taylor \& Francis.

Kietzmann, J. (2008) Interactive innovation of technology for mobile work. European Journal of Information Systems, 17(3), 305-320.

Kim, M., Chang, Y., Park, M.-C., \& Lee, J. (2015) The effects of service interactivity on the satisfaction and the loyalty of smartphone users. Telematics and Informatics, 32(4), 949-960.

Kim, S. S., \& Malhotra, N. K. (2005) A Longitudinal Model of Continued IS Use: An Integrative View of Four Mechanisms Underlying Postadoption Phenomena. Management Science, 51(5), 741-755.

Kim, Y. B. (2010) Real-time Analysis of Time-based Usability and Accessibility for Human Mobile-Web Interactions in the Ubiquitous Internet. Journal of Universal Computer Science, 16(15), 1953-1972.

Kincheloe, J. L., \& McLaren, P. (2002) Rethinking critical theory and qualitative research. Ethnography and schools: Qualitative approaches to the study of education, 87-138.

Lamb, R., \& Kling, R. (2003) Reconceptualizing users as social actors in information systems research. MIS Quarterly, 27(2), 197-235.

Lanette, S., \& Mazmanian, M. (2018). The Smartphone Addiction Narrative is Compelling, but Largely Unfounded. In Extended Abstracts of the 2018 CHI Conference on Human Factors in Computing Systems (p. LBW023). ACM.

Lawler, S. (2002) Narrative in Ssocial Rresearch. London: Sage.

Lee, A. S., \& Hubona, G. S. (2009). A scientific basis for rigor in information systems research. MIS Quarterly, 33(2), 237-262.

Leonardi, P. M., \& Barley, S. R. (2008) Materiality and change: Challenges to building better theory about technology and organizing. Information and Organization, 18(3), 159-176.

Leong, T., Vetere, F., \& Howard, S. (2008) Abdicating choice: the rewards of letting go. Digital Creativity, 19(4), 233-243. 
Lin, P. C., \& Huang, Y. H. (2012) The influence factors on choice behavior regarding green products based on the theory of consumption values. Journal of Cleaner Production, 22(1), 11-18.

Llewellyn, S. (1999) Narratives in accounting and management research. Accounting, Auditing \& Accountability Journal, 12(2), 220-237.

Mazmanian, M. A., Orlikowski, W. J., \& Yates, J. (2005) Crackberries: The social implications of ubiquitous wireless e-mail devices. In C. Sorensen, Y. Yoo, K. Lyytinen \& J. I. DeGross (Eds.), Designing Ubiquitous Information Environments: Socio-Technical Issues and Challenges (Vol. 185, pp. 337-343)

Mazmanian, M., Orlikowski, W. J., \& Yates, J. (2013) The autonomy paradox: The implications of mobile email devices for knowledge professionals. Organization Science, 24(5), 1337-1357.

Mazmanian, M., Orlikowski, W., \& Yates, J. (2006) CrackBerries: The Social Implications of Ubiquitous Wireless E-Mail Devices, Designing Ubiquitous Information Environments: Socio-Technical Issues and Challenges: Springer, Boston.

Merleau-Ponty, M. (2012). Phenomenology of Perception. [Phénoménologie de la perception, 1945](trans: Landes, Donald A.). New York: Routledge.

Middleton, C., Scheepers, R., \& Tuunainen, V. K. (2014) When mobile is the norm: researching mobile information systems and mobility as post-adoption phenomena. European Journal of Information Systems, 23(5), 503-512.

Morgan, D. L. (1997). Focus Groups as Qualitative Research (2 ed.). Thousand Oaks, CA: SAGE Publications, Inc.

Morse, J. M., Barrett, M., Mayan, M., Olson, K., \& Spiers, J. (2002). Verification strategies for establishing reliability and validity in qualitative research. International journal of qualitative methods, 1(2), 13-22.

Norman, D. A. (2002) The design of everyday things (Vol. 16) New York: Basic Books

Nye, D. (1996) The Technological Sublime: Cambridge, MA: MIT Press.

Ortez de Guinea, A., \& Markus, M. L. (2009) Why Break the Habit of a Lifetime? Rethinking the Roles on Intention, Habit, and Emotion in Continuing Information Technology Use. MIS Quarterly, 33(3), 433444.

Park, B. W., \& Lee, K. C. (2011) An empirical analysis of online gamers' perceptions of game items: Modified theory of consumption values approach. Cyberpsychology, Behavior, and Social Networking, 14(7-8), 453-459.

Pitt, L. F., Parent, M., Junglas, I., Chan, A., \& Spyropoulou, S. (2011) Integrating the smartphone into a sound environmental information systems strategy: Principles, practices and a research agenda. The Journal of Strategic Information Systems, 20(1), 27-37.

Polkinghorne, D. E. (2007) Validity issues in narrative research. Qualitative Inquiry, 13(4), 471-486.

Pope, N. (2001) An examination of the use of peer rating for formative assessment in the context of the theory of consumption values. Assessment \& Evaluation in Higher Education, 26(3), 235-246.

Pousa, C. E., \& Nuñez, J. F. (2014) Why do consumers buy Fair Trade products? An evolutionary perspective using the Theory of Consumption Values. Journal of Management and Sustainability, $4(2), 1-11$.

Prasopoulou, E., Pouloudi, A., \& Panteli, N. (2006) Enacting new temporal boundaries: the role of mobile phones. European Journal of Information Systems, 15(3), 277-284.

Remenyi, D., \& Williams, B. (1996) The nature of research: Qualitative or quantitative, narrative or paradigmatic? Information Systems Journal, 6(2), 131-146.

Richardson, L., \& St. Pierre, E. A. (2005). Writing: A Method of Inquiry. In N. K. Denzin \& Y. S. Lincoln (Eds.), The Sage handbook of qualitative research (pp. 959-978). Thousand Oaks, CA: Sage Publications Ltd.

Rogers, E. M. (1995) Diffusion of Innovations (4th ed.): The Free Press.

Sanday, P. R. (1983). The Ethnographic Paradigm. In J. Van Maanen (Ed.), Qualitative Methodology (pp. 19-36). Beverly Hills, CA: Sage Publications.

Sandelowski, M. (1991) Telling Stories: Narrative Approaches in Qualitative Research. Journal of Nursing Scholarship, 23(3), 161-166.

Schmidt, A. (2000) Implicit human computer interaction through context. Personal and Ubiquitous Computing, 4(2), 191-199. 
Schutz, A. (1962). Concept and Theory Formulation in the Social Sciences. In M. Natanson (Ed.), Collected Papers I: The Problems of Social Reality (pp. 48-66). Boston, MA: Kluwer Academic Publishers.

Seth, J. N., Newman, B. I., \& Gross, B. L. (1991) Why We Buy What We Buy: A Theory of Consumption Values. Journal of Business Research, 22, 159-170.

Sheth, J. N., Newman, B. I., \& Gross, B. L. (1991) Consumption Values and Market Choices: Theory and Applications. Cincinnati: South-Western Publishing Co.

Skageby, J. (2011) Pre-produsage and the remediation of virtual products. New Review of Hypermedia and Multimedia, 17(1), 141-159.

Stein, M.-K., Newell, S., Wagner, E. L., \& Galliers, R. D. (2015) Coping with Information Technology: Mixed Emotions, Vacillation, and Nonconforming Use Patterns. MIS Quarterly, 39(2), 367-392.

Straub, D., Limayem, M., \& Karahanna-Evaristo, E. (1995) Measuring system usage: Implications for IS theory testing. Management Science, 41(8), 1328-1342.

Tolmie, P., Pycock, J., Diggins, T., McLean, A., \& Karsenti, A. (2002) Unremarkable Computing. CHI '02 Proceedings of the SIGCHI Conference on Human Factors in Computing Systems, Pages 399-406

Turel, O., Serenko, A., \& Bontis, N. (2010) User acceptance of hedonic digital artifacts: A theory of consumption values perspective. Information \& Management, 47(1), 53-59.

Turel, O., Serenko, A., \& Giles, P. (2011). Integrating technology addiction and use: An empirical investigation of online auction users. MIS Quarterly, 35(4), 1043-1062.

Van der Heijden, H. (2004) User Acceptance of Hedonic Information Systems. MIS Quarterly, 28(4), 695704.

Vandewater, E. A., \& Lee, S. J. (2009). Measuring children's media use in the digital age: issues and challenges. American Behavioral Scientist, 52(8), 1152-1176.

Venkatesh, V. Thong, J., \& Xu, X. (2012) Consumer Acceptance and Use of Information Technology: Extending the Unified Theory of Acceptance and Use of Technology. MIS Quarterly, 36(1), 157-178.

Walsh, I. (2014) A strategic path to study IT use through users' IT culture and IT needs: A mixed-method grounded theory. The Journal of Strategic Information Systems, 23(2), 146-173.

Walsh, I., Gettler-Summa, M., \& Kalika, M. (2016) Expectable use: An important facet of IT usage. The Journal of Strategic Information Systems, 25(3), 177-210.

Walsham, G. (1995) Interpretive case-studies in is research - nature and method. European Journal of Information Systems, 4(2), 74-81.

Weiser, M. (1991) The computer for the twenty-first century. Scientific American, 265(3), 94-104.

Yang, C. Y., \& Hsu, Y. C. (2011) Impact of Ergonomic and Social Psychological Perspective: A Case Study of Fashion Technology Adoption in Taiwan. International Journal of Human-Computer Interaction, 27(7), 583-605.

Yoo, Y. (2010) Computing in everyday life: A call for research on experiential computing. MIS Quarterly, $34(2), 213-231$. 